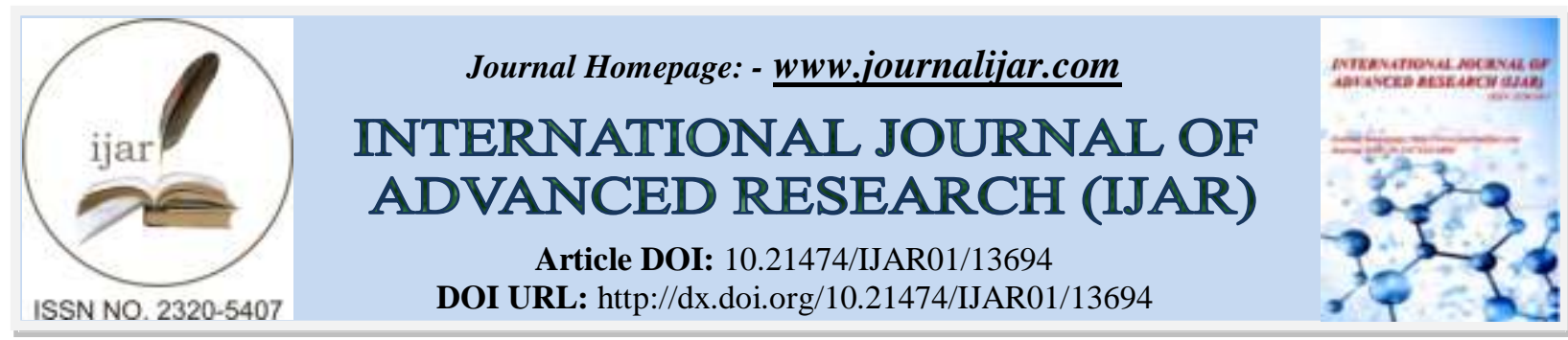

RESEARCH ARTICLE

\title{
EVALUATION OF C - REACTIVE PROTEIN AS A PROGNOSTICATOR OF THE COURSE OF COVID 19 DISEASE
}

\author{
Rani Kumaravelu, Priyadarshini Shanmugam, Nirupa Soundararajan, Alice Peace R. and Perumal \\ Jayaraman
}

\section{Manuscript Info}

............................

Manuscript History

Received: 31 August 2021

Final Accepted: 30 September 2021

Published: October 2021

\section{Keywords:}

C Reactive Protein,Covid 19, Sars Cov2, Inflammatory Marker, Prognostic Marker, Icu, Non-Icu

\section{Abstract}

Diagnosis of COVID 19 is based on clinical manifestations, history of exposure, positive CT scan findings and laboratory tests. Inflammation plays a key role in pathogenesis of COVID 19. CRP is an acute phase protein in the serum and is also a surrogate marker for the pro inflammatory cytokine IL 6 . Significant rise in CRP indicates clinically relevant inflammation. Aim and Objectives: To analyse the CRP levels in COVID 19 infected patients and to validate CRP as an indicator of the severity of SARS CoV 2 infection. Materials and Methods: This retrospective study was carried out at Chettinad Hospital and Research Institute, a tertiary care hospital situated on the outskirts of Chennai, India, for a period of 4 months. A total of 10263 patients were tested for COVID-19 by RT PCR. Viral RNA Extraction was automated and SARS CoV2 RTPCR performed with ROTOR GENE Q(QIAGEN) using SD Biosensor Real Time PCR kit. The CRP levels were measured using QDx Instacheck Fluorescence immunoassay system, Indianapolis, IN. Results: Among 10263 patients, 2694 (26.2\%) patients tested SARS CoV-2 positive. CRP levels were measured for 1472 SARS CoV 2 patients (including both OP and IP). Among them $745(50.6 \%)$ patients were found to be CRP reactive. Of the CRP reactive patients, 7 patients $(0.9 \%)$ were $<18$ years, 190 patients (25.5\%) were between 18 - 45 years and 548 patients $(73.5 \%)$ were $>45$ years. Of the 592 patients with elevated CRP levels, 167 patients were from ICU and 425 patients were from non-ICU. Highly elevated CRP levels of $>100 \mathrm{mg} / \mathrm{L}$ were found in $65 \%(\mathrm{n}=109)$ of the COVID positive ICU patients and $23 \%(\mathrm{n}=101)$ of the non-ICU patients. Increased CRP levels were noted in SARS CoV- 2 infected individuals. Elevated CRP was common among elder patients aged $>45$ years and in males. Conclusion This study concludes that the significant rise of CRP levels was noted in hospitalized SARS CoV 2 positive patients aged > 45 years. Thus, estimating the early rise of serum CRP levels in SARS CoV-2 patients is a well affordable and less invasive parameter to guide the clinicians that is readily available in all the health care centers. 


\section{Introduction:-}

In December 2019, pneumonia cases associated with a novel Coronavirus were reported in Wuhan City, Hubei Province of China. In February 2020, The International Committee on Taxonomy of Viruses (ICTV) named the novel virus severe acute respiratory syndrome coronavirus 2 (SARS-CoV-2), while the World Health Organization (WHO) declared "coronavirus disease" (COVID-19) as the official name of the disease caused by the virus ${ }^{1}$ On January 31, 2020, WHO declared corona virus disease as a public health emergency of international concern and subsequently on $11^{\text {th }}$ March 2020 WHO declared it as a pandemic.COVID-19 patients with mild illness have flu-like symptoms with or without dry cough and mild fever $\left(37.8^{\circ} \mathrm{C}\right) .^{2}$ Patients with severe COVID symptoms present with dyspnoea due to acute atypical pneumonia resulting in acute lung injury which progresses on to multi organ failure and eventually lead to a life-threatening situation in patients with underlying comorbidities. ${ }^{3}$ The most common comorbidities include diabetes, chronic obstructive pulmonary disease (COPD), cardiovascular disease, hypertension, malignancies and individuals with compromised immune system. ${ }^{4} \mathrm{C}$-Reactive protein is an acute phase protein that has the binding specificity for the phosphocholine determinant of cell wall C polysaccharide of Streptococcus pneumoniae. It is an acute phase reactant and is a surrogate marker for the pro inflammatory cytokine IL 6 and is synthesized by the liver and adipocytes in response to acute and chronic inflammatory conditions SARS $\mathrm{CoV}$ and MERS CoV-infected patients had elevated liver enzymes and varying degrees of hepatic injury. Studies have reported that $\mathrm{C}$ reactive protein level was found to be significantly higher in patients with elevated alanine aminotransferase. ${ }^{5}$ Therefore, exaggerated hyper inflammatory response (cytokine storm) in COVID 19 disease can lead to hepatic injury.

Significant rise in CRP indicates acute infection and is a crucial marker to gauge the inflammatory response against the invading pathogen and also strongly correlates with mechanical ventilation or mortality. ${ }^{6}$ Also elevated CRP levels were found to be consistent with abnormal radiological findings of COVID-19 pneumonia like bilateral ground-glass opacities (GGOs) and consolidation with a peripheral and posterior lung distribution. ${ }^{7,8,9}$

Therefore, in this study we analyzed the CRP levels in COVID 19 infected patients in order to predict the severity and prognosis of the disease.

\section{Materials and Methods:-}

This retrospective study was carried out at Chettinad Hospital and Research Institute, a tertiary care hospital situated on the outskirts of Chennai, Chengalpattu district (Tamilnadu), for a period of 3 months. Nasopharyngeal and throat swabs were collected from outpatients and inpatients, and SARS CoV2 RTPCR was performed according to ICMR guidelines. This study was initiated after receiving the Institutional Human ethics committee clearance. A total of 10263 suspected COVID 19 patients, both OP and IP were tested. Nasopharyngeal and throat swabs were collected from these. Blood samples for CRP were collected from patients in a Red topped vacutainer, following strict asepsis. Serum was separated by centrifugation and used for CRP analysis.

SARS-CoV2 viral RNA extraction and purification from nasopharyngeal and throat swabs was performed using QIAamp Viral RNA Mini Kit plus QIAamp Viral RNA Mini Accessory Set (cat. no. 1048147) in QIAcube automated nucleic acid extractor.Real Time reverse transcriptase PCR assay for SARS-CoV2 detection was performed in Rotor Gene Q using STANDARD M nCoV Real Time Detection kit from SD Biosensor (ICMR approved) that qualitatively detects the SARS CoV 2 target genes ORF 1ab (RdRp) gene and E gene. This kit is based on the TaqMan probe real- time fluorescent PCR technology. The $\mathrm{Ct}$ (cycle threshold) cut off value less than or equal to 36 was considered positive for ORF 1ab (RdRp) gene and $\mathrm{E}$ gene.

CRP levels were measured using the QDx Instacheck hsCRP immunoassay system, based on fluorescence immunoassay technique. In brief, the patient's sample was mixed with the detection buffer and during this process, the fluorochrome labelled detector antibodies (anti-CRP) bind to CRP in the sample. When this sample was loaded on to the sample well in the test cartridge, it migrated through the nitrocellulose matrix of the test strip. The fluorochrome labelled detector antibody-analyte (CRP) complexes get captured on to the capture antibodies (antiCRP) which have been immobilised on the test line on the test strip. As a result, the complexes of the captured antibody-analyte (CRP) get accumulated at the test line on the test cartridge membrane. The more the amount of CRP in the sample, more of the antibody analyte complex gets accumulated. On inserting the test cartridge in the QDx Instacheck Reader, the laser light illuminates the test cartridge membrane and fluorescence is triggered from the fluorochrome labelled complexes of CRP. Intensity of fluorescence was scanned and converted into an electric 
signa and the CRP concentration was computed based on a preprogramed calibration. The result was displayed by the QDx Instacheck Reader, quantitatively in terms of $\mathrm{mg} / \mathrm{L}$. The CRP range of $>10 \mathrm{mg} / \mathrm{L}$ indicated an acute inflammatory condition.

\section{Results:-}

The study population comprised of patients belonging to various age groups, ranging from 0 month -70 years. Total number of patients screened for SARS-CoV2 RTPCR was 10263, among which 2694 (26.2\%) patients were positive for COVID-19 (Fig: 1). Among 2694 COVID-19 positive patients, 1472 patients were screened for CRP and of these, $745(50.6 \%)$ patients had elevated C - reactive protein levels more than 10mg/L. In the early stage of the disease the patients with elevated CRP levels had significant correlation with lung lesions and disease severity. Males were at higher risk of developing severe symptoms of COVID-19 when compared to females.

Of the 2694 COVID positive patients, 1168 were inpatients and the 1526 were treated as outpatients. CRP was elevated in $153(20.5 \%)$ and 592 (79.4\%) of OP and IP COVID positive patients respectively. (Fig: 2). Elevated CRP levels remains as an significant indicator for patients who require hospitalization when compared to patients with normal CRP levels.

A total of 592 inpatients showed elevated CRP levels. Among them 167 ICU and 425 non-ICU patients showed mild to highly elevated CRP levels (Fig: 3) However 65\% $(n=109)$ of the COVID positive ICU patients had highly elevated CRP levels of >100mg/L whereas $23 \%(n=101)$ of the non-ICU patients had CRP levels >100mg/L (Fig: 4)

Of the 10263 samples tested for SARS-CoV2, 436 patients belonged to <18 years of age, 6554 patients belonged to 18-45 years of age and 3273 patients belonged to $>45$ years of age. Among the patients belonging to $<18$ years age group 137(31.4\%) were SARS-CoV2 RTPCR positive and 7 (5.10\%) had elevated CRP levels respectively. In the 18-45 years age group 1372 (20\%) were SARS-CoV2 RTPCR positive and 190 (13.84\%) had elevated CRP levels respectively. Among the patients belonging to >45 years of age 1185(36.2\%) were SARS-CoV2 RTPCR positive and 548 (46.24\%) had elevated CRP levels respectively. (Fig: 5)

Among 153 COVID positive outpatients with increased CRP levels, 112 patients were male, and 41 patients were female. Among 592 Covid-19 positive inpatients with elevated CRP levels, 395 patients were male, and 197 patients were female. There was no significant difference between the percentage of males and females with elevated CRP among the Covid 19 positive patients (Table $1 \& 2$ )

\section{Discussion:-}

A total of 10263 nasopharyngeal and throat swabs were collected from suspected COVID 19 inpatients and outpatients. Among them 2694 (26.2\%) were SARS CoV2 positive by RTPCR as given in (Fig 1). 745 (27.65\%) patients had elevated CRP levels among the 2694 Covid-19 positive patients as given in (Fig 2). Among the 745 covid positive patients with elevated CRP levels, 7 (5.10\%) patients were <18 years, $190(13.84 \%)$ patients were of the age group 18 to 45 years whereas 548 (46.24\%) patients were >45 years, as given in (Fig: 5). The present study revealed that the elevated CRP was higher among patients belonging to the age group above 45 years, which was similar to the study reported by Chen $\mathrm{W}$ et al. ${ }^{10}$ Also, significant rise in CRP levels were elicited in critically ill hospitalized patients when compared to COVID positive non-ICU and outpatients and this was found to be consistent with the study by Milad Sharifpour et al(Fig:4 \&Table:1). ${ }^{11}$ There was no significant difference observed between male and female COVID positive patients with elevated CRP levels (Table:2).

C-reactive protein is a nonspecific, acute-phase, inflammatory protein which is expressed in response to tissue injury and other inflammatory conditions and the levels rise within 24 to 72 hours and decrease exponentially within $18-20$ hours with the resolution of the inflammatory condition. ${ }^{12,13,14}$ Evaluation of C - reactive protein is easy to perform and is much cost-effective. Baseline CRP levels are greatly affected by few factors like age, sex, lipid profile, smoking habits etc., ${ }^{15}$ Also, an elevated CRP level is considered as an important marker of vascular inflammation and associated cardiovascular disease. Monocytes exhibit an enhanced production of interleukins- 6 in response to CRP and this considered as a possible link between CRP and cardiovascular disease.

In patients with sepsis, CRP levels $>100 \mathrm{mg} / \mathrm{L}$ have been identified as an independent predictor of length of ICU stay in patients who fulfil Sepsis-3 criteria and 30-day mortality. ${ }^{16}$ 
Table/Figure Captions:

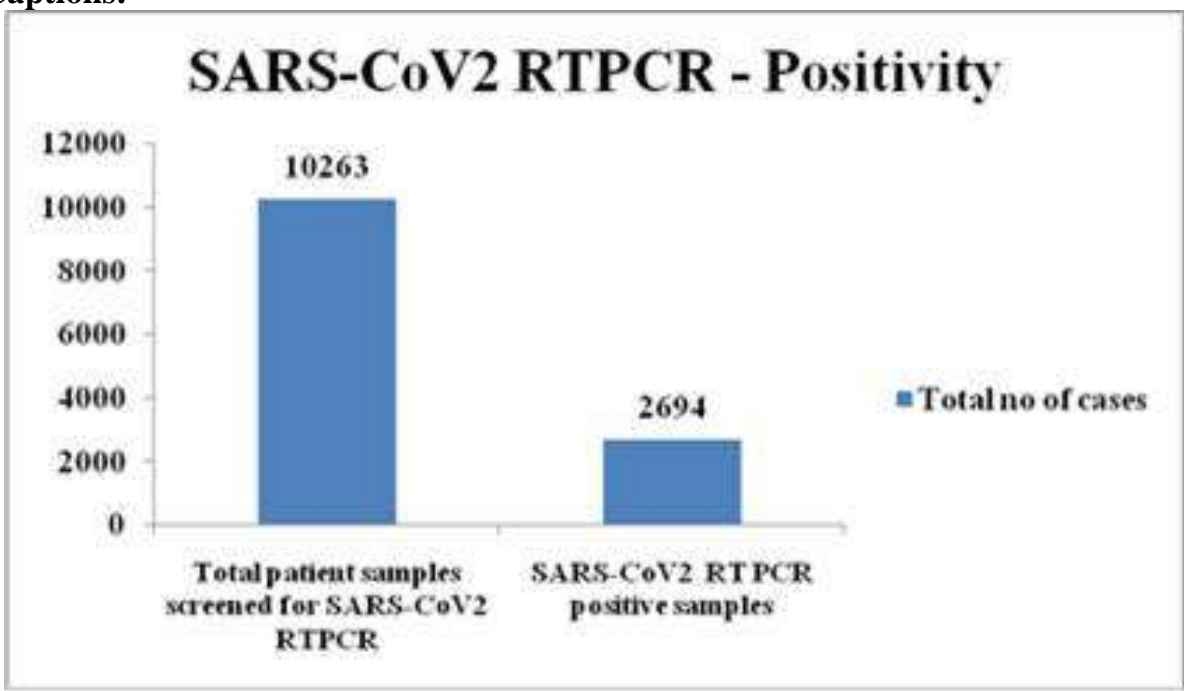

Fig 1:- Total samples tested for SARS-CoV2 RT PCR and the number of samples tested positive for SARS-CoV2.

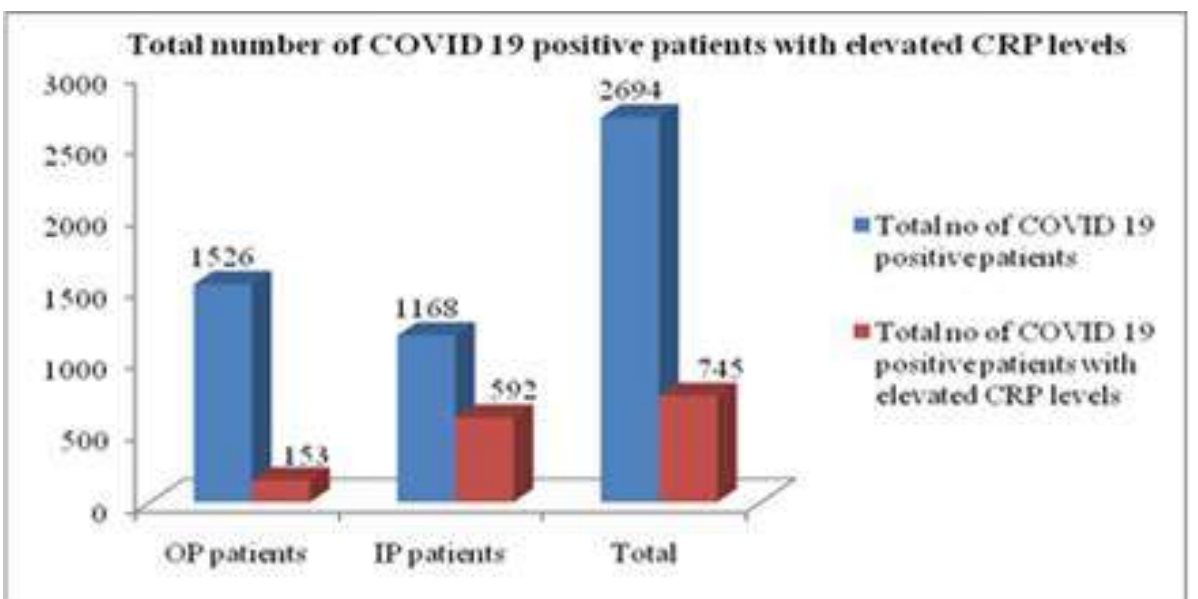

Fig 2:- Total number patients positive for COVID -19 and the number of COVID 19 patients with elevated CRP levels.

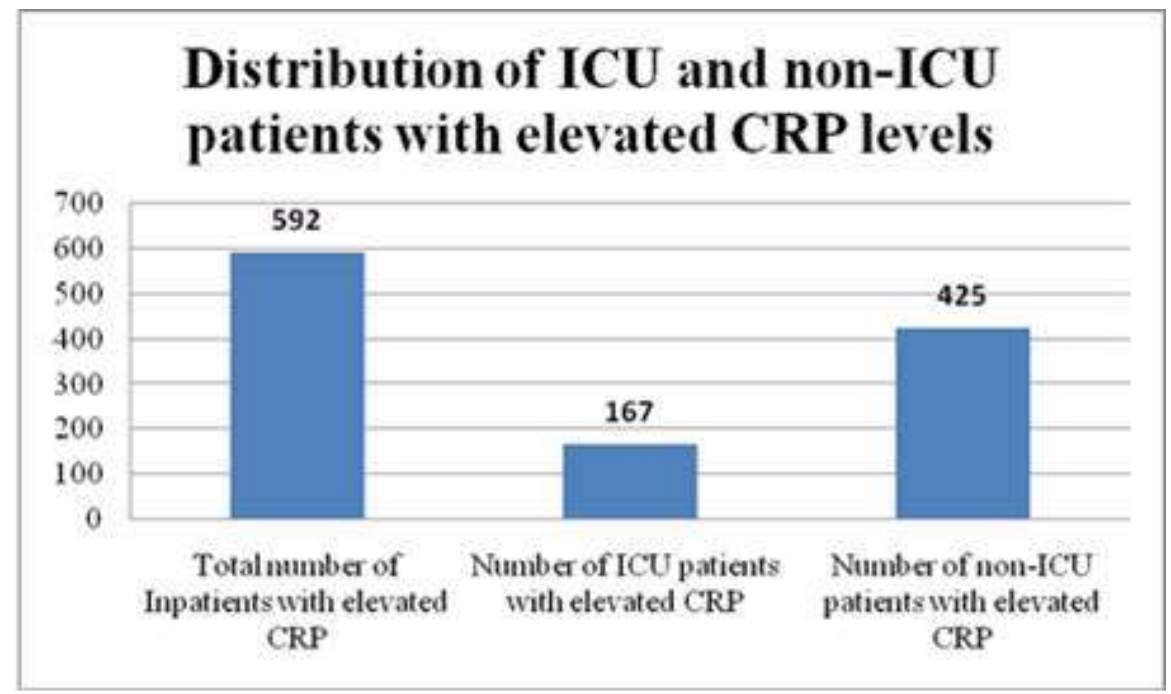

Fig 3:- Distribution of ICU and non-ICU patients with elevated CRP levels. 


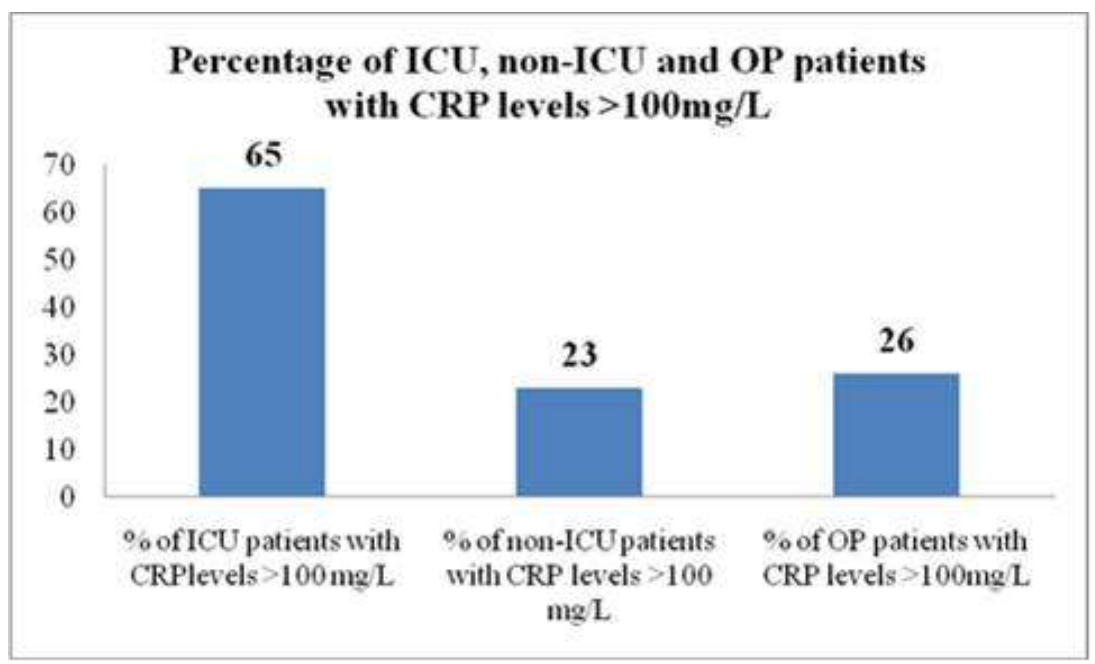

Fig 4:- Percentage of ICU, non-ICU and OP patients with elevated CRP levels of $>100 \mathrm{mg} / \mathrm{L}$.

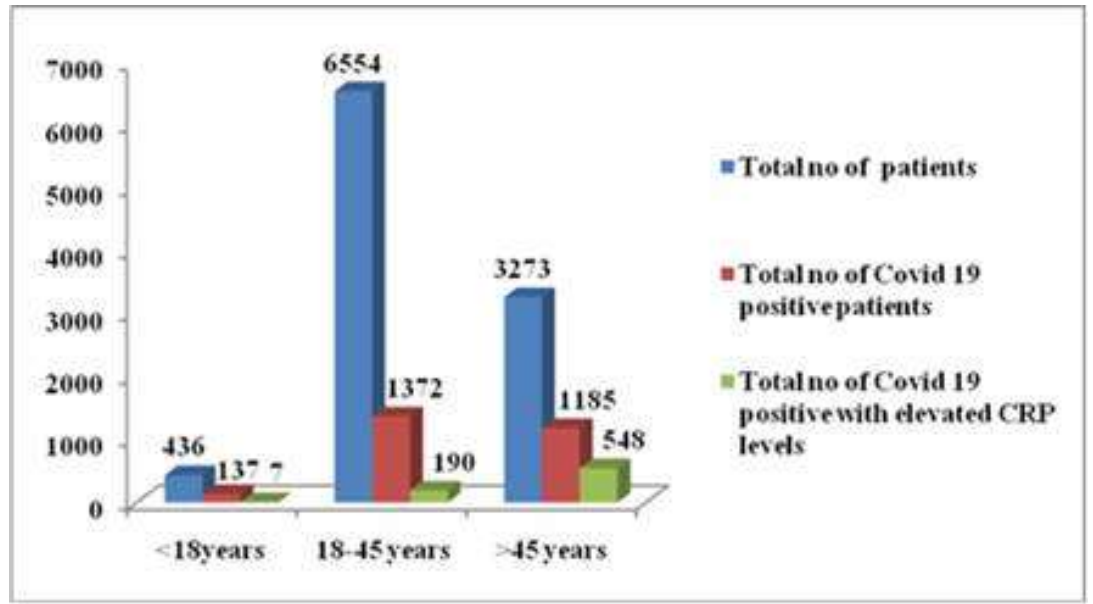

Fig 5:- Age wise distribution of COVID 19 positive patients with elevated CRP levels.

Table 1:- Sex wise distribution of OP and IP patients with elevated CRP levels.

\begin{tabular}{|c|c|c|c|c|c|c|c|}
\hline \multirow{2}{*}{$\begin{array}{l}\text { Patient } \\
\text { Gender }\end{array}$} & \multicolumn{3}{|l|}{ OP } & \multicolumn{3}{|l|}{ IP } & \multirow[b]{2}{*}{$\begin{array}{lr}\text { Total } & \\
\text { Total number } \\
\text { of } & \text { CRP } \\
\text { positive } & \\
\text { patients } & \\
\end{array}$} \\
\hline & $\begin{array}{l}\text { Total no. of } \\
\text { patients } \\
\text { tested for } \\
\text { CRP }\end{array}$ & $\begin{array}{l}\text { No of of } \\
\text { patients with } \\
\text { elevated } \\
\text { CRP levels }\end{array}$ & $\begin{array}{l}\% \\
\text { patients } \\
\text { with } \\
\text { elevated } \\
\text { CRP }\end{array}$ & $\begin{array}{l}\text { Total no. of } \\
\text { patients } \\
\text { tested for } \\
\text { CRP }\end{array}$ & $\begin{array}{l}\text { No of } \\
\text { patients with } \\
\text { elevated } \\
\text { CRP levels }\end{array}$ & $\begin{array}{l}\% \\
\text { patients } \\
\text { with } \\
\text { elevated } \\
\text { CRP }\end{array}$ & \\
\hline Males & 280 & 112 & $40 \%$ & 693 & 395 & $56.9 \%$ & $507(68 \%)$ \\
\hline Females & 106 & 41 & $38.6 \%$ & 371 & 197 & $53.0 \%$ & $248(33.2 \%)$ \\
\hline Total & 386 & 153 & $39.6 \%$ & 1064 & 592 & $55.6 \%$ & $745(51.3 \%)$ \\
\hline
\end{tabular}

Table 2:- Age and gender wise distribution COVID positive patients with increased CRP levels.

\begin{tabular}{|l|l|l|l|l|l|l|}
\hline Age & \multicolumn{2}{|c|}{$<18$ years } & \multicolumn{2}{c|}{18 to 45 years } & \multicolumn{2}{c|}{$>45$ years } \\
\hline $\begin{array}{l}\text { CRP } \\
\text { Elevated }\end{array}$ & $\begin{array}{l}\text { Number } \\
\text { of positives }\end{array}$ & $\%$ of positives & $\begin{array}{l}\text { Number } \\
\text { of positives }\end{array}$ & $\%$ of positives & $\begin{array}{l}\text { Number } \\
\text { of positives }\end{array}$ & $\%$ of positives \\
\hline Males & 4 & $57.1 \%$ & 141 & $74.2 \%$ & 368 & $67.2 \%$ \\
\hline Females & 3 & $42.9 \%$ & 49 & $25.8 \%$ & 180 & $32.9 \%$ \\
\hline Total & 7 & 190 & 548 & \\
\hline
\end{tabular}




\section{Conclusion:-}

C- Reactive protein level is positively correlated to the severity of Covid 19. Patients with higher levels of CRP required longer hospitalization and helps to assess patients with moderate to severe Covid 19 pneumonia from those with mild condition. The diagnosis and treatment of novel COVID-19 pandemic is still in the exploratory stage. Though the advancement in medical techniques has introduced valuable testing modalities like CT scan and RTPCR, the affordability of these tests is still a challenge for the economically burdened. Therefore, nonspecific parameter like CRP is found to be cost effective, less invasive and also much helpful in early stage of COVID 19 pneumonia. ${ }^{20}$ From the current study it was concluded that significant rise of CRP levels is noted in patients above 45 years of age and associated with comorbidities which in turn denote the severity and prognosis of COVID-19 disease. To conclude, estimating serum CRP can guide the clinicians to categorise the Covid-19 positive patients and to assess the disease severity and prognosis and thereby help in decreasing the disease complication and improving patient's quality of life.

\section{References:-}

1. Zhu N, Zhang D, Wang W, Li X, Yang B, Song J, Zhao X, Huang B, Shi W, Lu R, Niu P. A novel coronavirus from patients with pneumonia in China, 2019. New England journal of medicine. 2020 Jan 24. Zhu N, Zhang D, Wang W, Li X, Yang B, Song J, Zhao X, Huang B, Shi W, Lu R, Niu P. A novel coronavirus from patients with pneumonia in China, 2019. New England journal of medicine. 2020 Jan 24.

2. Huang C, Wang Y, Li X, Ren L, Zhao J, Hu Y, Zhang L, Fan G, Xu J, Gu X, Cheng Z. Clinical features of patients infected with 2019 novel coronavirus in Wuhan, China. The lancet. 2020 Feb 15;395(10223):497-506.

3. Lu R, Zhao X, Li J, Niu P, Yang B, Wu H, Wang W, Song H, Huang B, Zhu N, Bi Y. Genomic characterisation and epidemiology of 2019 novel coronavirus: implications for virus origins and receptor binding. The lancet. 2020 Feb 22;395(10224):565-74.

4. Lai CC, Shih TP, Ko WC, Tang HJ, Hsueh PR. Severe acute respiratory syndrome coronavirus 2 (SARS-CoV2) and coronavirus disease-2019 (COVID-19): The epidemic and the challenges. International journal of antimicrobial agents. 2020 Mar 1;55(3):105924.

5. Li L, Li S, Xu M, Zheng S, Duan Z, Chen Y, Li J. The level of plasma C-reactive protein is closely related to the liver injury in patients with COVID-19. medRxiv. 2020 Jan 1.

6. Wu Y, Potempa LA, El Kebir D, Filep JG. C-reactive protein and inflammation: conformational changes affect function. Biological chemistry. 2015 Nov 1;396(11):1181-97.

7. Yoon SH, Lee KH, Kim JY, Lee YK, Ko H, Kim KH, Park CM, Kim YH. Chest radiographic and CT findings of the 2019 novel coronavirus disease (COVID-19): analysis of nine patients treated in Korea. Korean journal of radiology. $2020 \mathrm{Apr} ; 21(4): 494$.

8. Chung M, Bernheim A, Mei X, Zhang N, Huang M, Zeng X, Cui J, Xu W, Yang Y, Fayad ZA, Jacobi A. CT imaging features of 2019 novel coronavirus (2019-nCoV). Radiology. 2020 Apr;295(1):202-7.

9. Chen W, Zheng KI, Liu S, Yan Z, Xu C, Qiao Z. Plasma CRP level is positively associated with the severity of COVID-19. Annals of clinical microbiology and antimicrobials. 2020 Dec;19:1-7.

10. Sharifpour M, Rangaraju S, Liu M, Alabyad D, Nahab FB, Creel-Bulos CM, Jabaley CS, Emory COVID-19 Quality \& Clinical Research Collaborative. C-Reactive protein as a prognostic indicator in hospitalized patients with COVID-19. PloS one. 2020 Nov 20; 15(11):e0242400.

11. Song F, Shi N, Shan F, Zhang Z, Shen J, Lu H, Ling Y, Jiang Y, Shi Y. Emerging 2019 novel coronavirus (2019-nCoV) pneumonia. Radiology. 2020 Apr; 295(1):210-7.

12. Clyne B, Olshaker JS. The C-reactive protein. The Journal of emergency medicine. 1999 Nov 1; 17(6):1019-25.

13. Gabay C, Kushner I. Acute-phase proteins and other systemic responses to inflammation. New England journal of medicine. 1999 Feb 11; 340(6):448-54.

14. Wang L. C-reactive protein levels in the early stage of COVID-19. Medecine et maladies infectieuses. 2020 Jun 1; 50(4):332-4.Wang L. C-reactive protein levels in the early stage of COVID-19. Med Mal Infect 2020; 50(4):332-4.

15. Sproston NR, Ashworth JJ. Role of C-reactive protein at sites of inflammation and infection. Frontiers in immunology. 2018 Apr 13; 9:754. s

16. Koozi H, Lengquist M, Frigyesi A. C-reactive protein as a prognostic factor in intensive care admissions for sepsis: a Swedish multicenter study. Journal of critical care. 2020 Apr 1; 56:73-9.

17. Wang JT, Sheng WH, Fang CT, Chen YC, Wang JL, Yu CJ, Chang SC, Yang PC. Clinical manifestations, laboratory findings, and treatment outcomes of SARS patients. Emerging infectious diseases. 2004 May; 10(5):818. 
18. Vasileva D, Badawi A. C-reactive protein as a biomarker of severe H1N1 influenza. Inflammation Research. 2019 Jan; 68(1):39-46.

19. Chen Y, Yang D, Cheng B, Chen J, Peng A, Yang C, Liu C, Xiong M, Deng A, Zhang Y, Zheng L. Clinical characteristics and outcomes of patients with diabetes and COVID-19 in association with glucose-lowering medication. Diabetes care. 2020 Jul 1;43(7):1399-407.

20. Chen N, Zhou M, Dong X, Qu J, Gong F, Han Y, Qiu Y, Wang J, Liu Y, Wei Y, Yu T. Epidemiological and clinical characteristics of 99 cases of 2019 novel coronavirus pneumonia in Wuhan, China: a descriptive study. The lancet. 2020 Feb 15; 395(10223):507-13. 